\title{
Assessing the feasibility of adaptation options: methodological advancements and directions for climate adaptation research and practice
}

\author{
Chandni Singh $^{1} \cdot$ James Ford $^{2} \cdot$ Debora Ley $^{3} \cdot$ Amir Bazaz $^{1} \cdot$ Aromar Revi $^{1}$
}

Received: 23 April 2019 / Accepted: 18 May 2020 / Published online: 28 June 2020

(C) The Author(s) 2020

\begin{abstract}
The Paris Agreement put adaptation prominently on the global climate action agenda. Despite a surge in research and praxis-based knowledge on adaptation, a critical policy roadblock is synthesizing and assessing this burgeoning evidence. We develop an approach to assess the multidimensional feasibility of adaptation options in a robust and transparent manner, providing direction for global climate policy and identifying knowledge gaps to further future climate research. The approach, which was tested in the IPCC Special Report on $1.5{ }^{\circ} \mathrm{C}$ (SR1.5) to assess 23 adaptation options, is underpinned by a systematic review of recent literature, expert elicitation, and iterative peer review. It responds to the challenge of limited agreement on adaptation indicators, lack of fine-scale adaptation data, and challenges of assessing synergies and trade-offs with mitigation. The findings offer methodological insights into how future assessments such as the IPCC Assessment Report (AR) six and regional, national, and sectoral assessment exercises could assess adaptation feasibility and synthesize the growing body of knowledge on climate change adaptation.
\end{abstract}

Keywords Climate change $\cdot$ Adaptation $\cdot$ Feasibility assessment $\cdot$ Synergies and trade-offs $\cdot$ IPCC

Significance statement: The climate change adaptation literature is growing exponentially, and various methods have been developed to assess and synthesize it. In the article, we detail a methodology for conducting a global assessment of the feasibility of adaptation options. We use a six-dimensional feasibility assessment framework which is unique in that it (1) presents an up-to-date, transparent, and robust review of current adaptation literature; (2) develops a methodological approach to undertake a multidimensional assessment of different adaptation options, thus moving beyond technological or economic assessments that dominate the field; (3) analyses the synergies and trade-offs between adaptation and mitigation, so far a critical gap in the literature; and (4) identifies current knowledge gaps across the adaptation space.

Electronic supplementary material The online version of this article (https://doi.org/10.1007/s10584-02002762-x) contains supplementary material, which is available to authorized users.

James Ford

j.ford2@leeds.ac.uk

Extended author information available on the last page of the article 


\section{Introduction: The need for rigorous, transparent adaptation feasibility assessments}

Climate change research is growing exponentially with the literature doubling every 5-6 years (Haunschild et al. 2016). While research across all topics are rising by $4 \%$ annually, climate change research has grown at an astounding 16\% (Minx et al. 2017). At this rate, the literature to be reviewed for the IPCC's sixth assessment (AR6) is projected to span between 270,000 and 330,000 publications (Minx et al. 2017). Adaptation research has also grown rapidly: articles highlighting adaptation more than doubled between 2008 and 2011 (Bassett and Fogelman 2013) and grew by 150\% from 2011 to 2014 (Webber 2016).

Given this 'big literature' challenge (Minx et al. 2017), adaptation experts have been grappling with ways to synthesize this evidence to inform policy and practice (Ford and Pearce 2010; Berrang-Ford et al. 2015; Webber 2016). There are a range of approaches to assess and synthesize large bodies of knowledge, from rapid evidence assessments (McKinnon 2015; Sutherland and Wordley 2018) and systematic literature reviews to meta-analyses and expert-elicited scoping (Snilstveit et al. 2013; Berrang-Ford et al. 2015; Sutherland and Wordley 2018).

In climate change vulnerability and adaptation research, the IPCC's expert-driven process of distilling advancements in climate research has been a long-held benchmark of good practice. However, it has been criticized for being biased towards peer-reviewed articles, which potentially discount practitioner knowledge (Howarth et al. 2017), projecting an 'observational, top-down account' (Viner and Howarth 2014) that is often not policy relevant (Beck 2011) or contextual (Livingston et al. 2018), and for lacking transparency in literature selection and appraisal (Ford and Pearce 2010; Ford et al. 2016). Consequently, vulnerability and adaptation researchers have repeatedly called for developing metrics and processes to undertake rigorous and transparent assessments of different adaptation options (Ford and Pearce 2010; Berrang-Ford et al. 2015) to enable investment and track implementation (Brooks et al. 2013). There are few comprehensive assessments comparing the feasibility of different adaptation options. While the feasibility of some options in certain sectors has been examined (e.g. feasibility of climate smart agriculture in developing countries (Thornton et al. 2018)), these typically do not discuss synergies and trade-offs between options (Porter et al. 2017).

In response to these challenges, and as authors of the IPCC Special Report on the Impacts of $1.5{ }^{\circ} \mathrm{C}$ of Global Warming tasked with 'assessing current and emerging adaptation and mitigation options, .... and associated opportunities and challenges', we developed an iterative, expert-driven process to assess the feasibility of adaptation options (de Coninck et al. 2018). Using the list of options in the AR5 as a starting point, the multidimensional assessment moves beyond the IPCC AR5's analysis of adaptation options and needs (Noble et al. 2014), which while comprehensive and cross-sectoral, did not assess synergies and trade-offs between options, examine which options are more feasible than others, document mitigation co-benefits or trade-offs, or provide line of sight in terms of frameworks used to assess options.

In this paper, we articulate an assessment framework that helps synthesize large volumes of literature using a rigorous and transparent process. This is intended to support the IPCC's current format of layering information, which goes from the policy-facing Summary for Policymakers, to key messages in the Executive Summaries of individual chapters, which are evidenced through detailed bibliographies. The feasibility assessment framework is 
presented as a methodological advancement to inform adaptation research and practice in a policy-relevant and solutions-oriented manner.

Apart from methodological challenges, there is also a significant intellectual challenge that faces the IPCC. The SR1.5 was the first time in the 30-year history of the IPCC that a joint adaptation and mitigation assessment was undertaken. Mismatches in metrics used across adaptation and mitigation; evidence gaps, especially around topics such as the cost and potential scalability of an option; and developing a global analysis with uneven regional spread were significant challenges. In practice, however, coordinating, sequencing, and prioritizing adaptation and mitigation actions are imperative to minimize climate risks and impacts. With climate change research agendas increasingly moving away from 'proving the existence and measurability of anthropogenic climate change' to finding 'ways of preparing for and responding to climate change in its many regional variations' (Livingston et al. 2018), we argue that multidimensional feasibility assessments such as described in this paper provide a way forward to build strong future climate science-policy linkages that cut across the adaptation-mitigaton divide.

\section{Assessing feasibility}

\subsection{A multidimensional feasibility assessment}

Commonly, feasibility is understood as a binary (feasible or not) or conditional (feasible if). In assessments of mitigation pathways or options, feasibility tends to denote a possibility or range of possibilities such as the possibility of meeting long-term climate targets (Riahi et al. 2015), comparing different decarbonization pathways and what they entail (Loftus et al. 2015), feasibility of different energy, and transport options (Jacobson et al. 2013; Schleussner et al. 2016).

In adaptation, there have been relatively fewer feasibility assessments partly because of the large, highly localized nature of adaptation evidence, range of often contradictory metrics to assess adaptation outcomes and effectiveness (Ford et al. 2013), and inadequate data on several aspects of feasibility such as adaptation costs, limits, and behavioural factors (Klein et al. 2014; van Valkengoed and Steg 2019). However, within the adaptation literature, there are several conceptual framings that have overlaps with feasibility such as adaptation effectiveness, readiness, and barriers and enablers to adaptation.

Adaptation effectiveness approaches tend to focus on the outcomes of adaptation and how the nature of these outcomes can justify adaptation investments. Traditional metrics to assess 'effective' or successful adaptation have typically been utilitarian analyses, which measure the cost-effectiveness of an adaptation option (e.g. calculating cost-benefit ratios to monitor present interventions and inform future adaptation actions). More recent justice-centric framings of successful adaptation focus on issues of inclusion and agency, highlighting how adaptation options (and processes to implement them) can create winners, losers, and tradeoffs (Schlosberg et al. 2017). It is critical to understand that these different framings of effectiveness privilege certain understandings of adaptation success and adaptation outcomes.

The framing of 'adaptation readiness' on the other hand assesses the likelihood that adaptation will take place and identifies areas where intervention is needed to improve preparedness (Ford and King 2015; Araos et al. 2017; Ford et al. 2017). It uses a scaffolding of six factors (political leadership, institutional organization, adaptation decision-making and 
stakeholder engagement, availability of usable science, dedicated funding, and public support) as essential to enable adaptation.

Another growing strand of research focusses on identifying adaptation barriers and enablers (Biesbroek et al. 2013; Eisenack et al. 2014; Barnett et al. 2015) as a way to enable adaptation implementation. Various exercises highlight sociocultural, economic, physical, technical, knowledge-based, institutional, and natural barriers to adaptation (Moser and Ekstrom 2010). Barriers approaches have been critiqued for their tendency to focus on negative, constraining factors at the cost of identifying enabling conditions, inadequate emphasis on adaptation processes, and treatment of barriers as distinct rather than intersecting and dynamic (Biesbroek et al. 2015; Ford et al. 2017). They, however, remain a popular way to assess adaptation feasibility because of their focus on identifying entry points for adaptation practice.

For the multidimensional feasibility assessment of adaptation options, we chose a barriers framing due to (1) the presence of an established and growing literature on adaptation barriers, (2) relatively better regional and sectoral coverage of adaptation barriers, and (3) the relative ease with which barriers and enablers are understood by policymakers and adaptation practitioners.

Drawing on the IPCC's SR1.5 (Allen et al. 2018; IPCC 2018), we define feasibility as 'the degree to which climate goals and response options are considered possible and/or desirable'. ${ }^{1}$ To understand what facilitates adaptation, we assessed feasibility across six dimensions: economic, technological, institutional, sociocultural, geophysical, and environmental feasibility. The six dimensions of the feasibility framework draw on existing adaptation literature that identify what factors determine if and how adaptation takes place (or not), including research on adaptation decision-making, barriers and opportunities, and monitoring and evaluation (Nelson et al. 2007; Moser and Ekstrom 2010; Park et al. 2012; Biesbroek et al. 2014a, 2014b; Ford and King 2015). Such a broad understanding of feasibility highlights how adaptation, whether technical, behavioural, or infrastructural, is mediated by the political environment and agents, sociocultural norms and contexts (Evans et al. 2016), cognitive factors (van Valkengoed and Steg 2019), economic incentives and benefits (Masud et al. 2017), and ecological conditions (Biesbroek et al. 2013).

It is critical to highlight that the six feasibility dimensions are dynamic (i.e. change over time), spatially variable, and interact. ${ }^{2}$ Some dimensions might be more time sensitive or sequential than others (e.g. in cases of extreme sea level rise, migration may no longer geophysically feasible). Changes in the feasibility of an adaptation option over time is essential to understand prioritization and sequencing of options, as well as how certain options can create path dependencies and locks-ins (i.e. over-reliance on particular options can 'out-crowd' other options in the future) or have maladaptive outcomes (e.g. present actions potentially increasing vulnerability or undermining adaptive capacity in the future) (Magnan et al. 2016; Gajjar et al. 2019). These effects require understanding interactions between near-term actions (e.g. short-term coping) and their long-term implications (e.g. maladaptation). Feasibility dimensions are also spatially variable, scale dependent, and context specific. For example,

\footnotetext{
${ }^{1}$ This definition of feasibility encompasses the notion of desirability, which is somewhat captured by one of the dimensions of the assessment framework - sociocultural acceptability. However, given the extremely contextual and individual/group-based nature of desirability, our global assessment of adaptation options did not capture desirability in the feasibility assessment framework.

${ }^{2}$ In this paper, we conduct a static, global scale feasibility assessment and do not report change over temporal or spatial scales. However, the framework is designed in a way that it can be conducted at different times and scales to capture these dynamics.
} 
local sociocultural norms, values, and beliefs; regional environmental resource limits; and specific development patterns (e.g. levels of urbanization) can shape overall feasibility (Biesbroek et al. 2013). These local conditions are also embedded in broader global-scale drivers such global markets, technological innovations, and policy agreements. Further, feasibility dimensions can interact and affect one another: infrastructure development and technology deployment (e.g. flood protection infrastructure or renewable energy megaprojects) depend on economic factors (costs, capacity to mobilize investments for R\&D), sociocultural factors (public acceptability), and institutional factors (legal and political support).

Overall, the mitigation and adaptation literature converges to agree that in practice, the feasibility of specific actions/technologies is multidimensional, differentiated across temporal and spatial scales, and differs from community to community and across regions. To capture this multidimensional, dynamic nature, feasibility assessments need to move away from being static assessments of certain attributes of options (e.g. economic feasibility) to more dynamic understandings of how multiple factors interact to shape overall feasibility. This is particularly challenging in global assessments such as those of the IPCC given that many of the feasibility dimensions will vary at regional to local levels and necessitate some degree of generalization and consideration of their associated interactions as identified across numerous studies.

\subsection{Methodological approach and process}

It is increasingly being argued that to implement effective and inclusive adaptation, we need to transform how we respond to and prepare for climate risks (Pelling et al. 2015). This transformation will involve sociotechnical transitions and building socioecological resilience (Gillard et al. 2016) through action across political, personal, and practical spheres (O'Brien 2017; Patterson et al. 2018). We operationalize this systems thinking and transformation imperative by examining four system transitions: energy, land and ecosystem, urban and infrastructure, and industrial system transitions. A fifth group of overarching adaptation options is considered which houses cross-system options such as disaster risk management (which is applicable to urban and infrastructure as well as energy and industrial system transitions) and climate services (an option with multiple implications for adaptation decision-making across scales, sectors, and actors).

Process The multidimensional feasibility of each adaptation option followed a 7-step process (Fig. 1). The seven steps move from defining the scope of the feasibility assessment (e.g. is it global or specific to a region, does it look at different system transitions or a particular one), indicator development (detailed in Table 1), and creating a database of relevant literature (steps 1-3), on conducting the assessment (steps 4-6). Step 7 articulates developing end products from the assessment. An optional step of assessing adaptation and mitigation synergies and trade-offs is indicated in grey (penultimate step).

Using the AR5 list of approximately 121 adaptation options as a starting point (Noble et al. 2014), we shortlisted 68 options for assessment, based on their relevance to $1.5{ }^{\circ} \mathrm{C}$ pathways and those in which the evidence base had developed since the AR5. These options were then clustered to remove redundancies and overlaps to a final list of 23 options. For example, all options related to energy infrastructure resilience, independent of their generation source, are categorized as 'resilience of power infrastructure'. An explanation on each adaptation option assessed is given in Supplementary Information 1. 


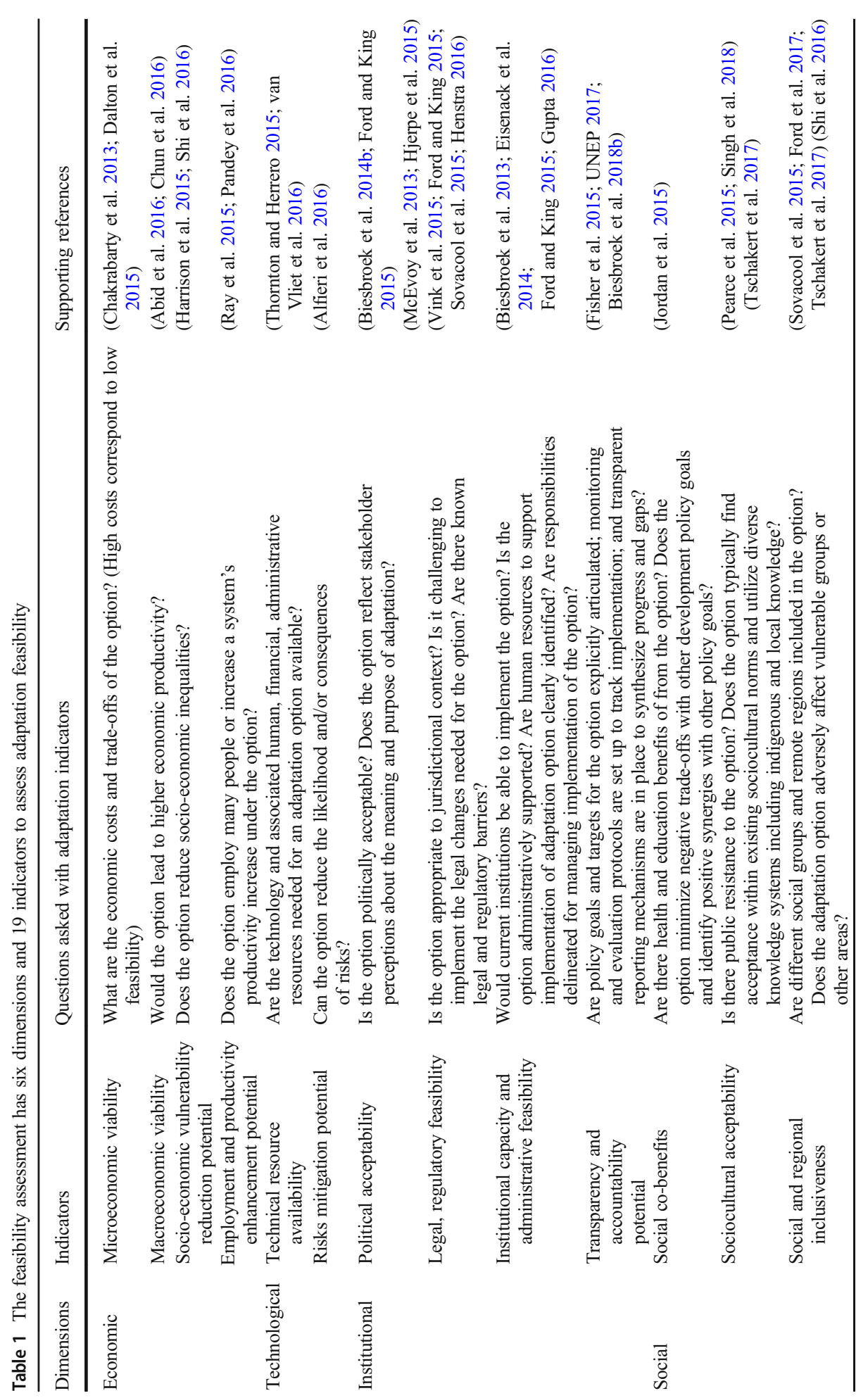




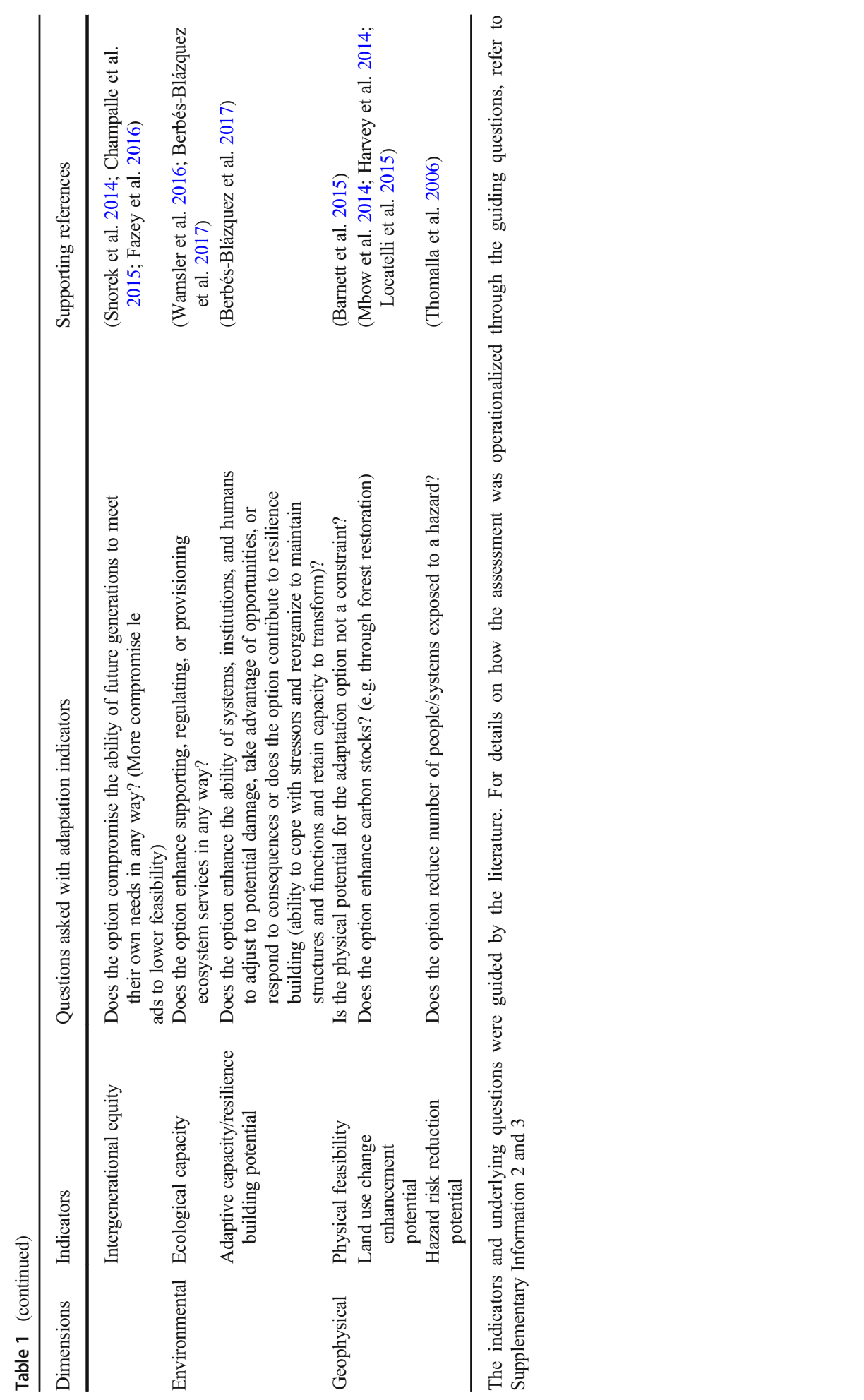




\section{Define scope}

Based on the scope of the study (global/ national/ local/ sectoral) identify system transitions and underlying adaptation options

\section{Develop indicators}

Across six feasibility dimensions, develop indicators through literature review and expert elicitation

\section{Create database}

Conduct literature review for each adaptation option at the indicator level

\section{Conduct assessment}

Assess each option at indicator-level giving scores of high, medium, low, low evidence, no evidence, not applicable

\section{Check robustness}

Cross-check each indicator-level score by 2-3 expert reviewers and adjust based on additional literature, regional diversity

\section{Combine indicators}

Combine indicator-level assessment (arithmetic mean of the relevant underlying indicators) to develop dimension-level score

\section{Assess mitigation synergies, trade-offs}

Assess positive or negative implications of adaptation option for mitigation (e.g. reduced carbon emissions)

\section{Report and visualise}

Report dimension-level assessment through spider charts, traffic light tables etc. Differentiation of an option's feasibility discussed in tables/text accompanying visuals.

Fig. 1 Seven-step process to assess feasibility. Optional step of assessing adaptation and mitigation synergies and trade-offs is indicated in grey

First, each option was assessed along six feasibility dimensions with a set of underlying indicators for each dimension (Table 1). The indicators were selected based on a review of adaptation scholarship and had underlying questions to guide the assessment, depicted in the third column of Table 1 .

The guiding questions were broad but, during the assessment, were 'applied' to each adaptation option by contextualizing to the specific option (an example of how this was done using 'climate services' is given in Table S4 of the Supplementary Information). Based on a review of literature, feasibility was assessed by examining whether an indicator blocks the feasibility of the option or not. Thus, the indicator-level assessment is captured if a certain indicator posed a barrier to the feasibility of the option or not. We use the idea of a barrier to denote a factor/process that blocks implementation of a certain option (Biesbroek et al. 2013; Eisenack et al. 2014; Barnett et al. 2015). ${ }^{3}$ Certain options that show low feasibility (i.e. have many barriers) might still be desirable or necessary in the light of local contexts. What the feasibility assessment shows is on which feasibility dimensions and indicators those barriers exist, thereby pointing towards possible first steps towards overcoming them. In doing so, it fulfils the aim of the feasibility assessment framework, which is to prioritize adaptation options, keeping decision-makers in mind.

Combining indicators A clear line of sight to the underlying evidence and literature was developed for each decision made during the assessment of 23 options, based on a total of 603 unique references. This involved carefully tracking the evidence for each option and mapping them onto specific indicators. Depending on the underlying literature base, the assessment indicates no evidence (NE), limited evidence (LE), where evidence was in two papers or less, or non-applicability (of the indicator) to the option (NA). For each feasibility dimension, overall feasibility was assessed as the arithmetic mean of the relevant underlying indicators.

\footnotetext{
${ }^{0}$ It is possible that this focus on identifying constraining factors (barriers) might overlook positive elements (enablers) such as strong leadership or financial and policy incentives for adaptation but this is somewhat ameliorated when reporting the results of the assessment, through examples of conditions under which specific adaptation options are highly feasible.
} 
Based on this, dimensions were classified as 'insignificant barriers' (2.5 to 3), 'mixed or moderate barriers' (1.5 to 2.5), or 'significant barriers' (below 1.5) to feasibility. Indicators assessed as NA, LE, or NE were not included in this overall assessment (see Table S1 and S2 in the Supplementary Information for details on the scoring schema). This 'mapping' process is important for transparency purposes and has not been used in previous IPCC assessments.

Ensuring robustness and transparency For each option, all the indicators were assessed drawing on three rounds of internal review to select literature and improve coverage of studies (e.g. to include evidence from different countries, peer reviewed, and grey literature) and remove biases. Each option's indicator-level assessment was validated by at least three authors. If indicator-level assessment differed, it was reconciled based on the literature; for regional or contextual differences in option-level feasibility, text was used to explain the differentiating factors (see 'context' column in Table 2). Ideally, the review of literature to conduct the indicator-level assessment would have been a systematic review (e.g. see BerrangFord et al. 2015). In our process, due to time constraints, we approached the assessment semisystematically basing it on standard practices of literature review (searching databases to achieve reference saturation) followed by careful and iterative reference checking, expert suggestions, and internal peer review. Through these multiple strategies, we assessed 603 unique references, which are listed in Supplementary Information 5.

In a step beyond typical feasibility assessments, we then assessed the evidence on whether implementing a particular adaptation option can have possible positive impacts (synergies) and negative impacts (trade-offs) with mitigation and vice versa (Section 3.2). When examined through the lens of system transitions, this synergy and trade-off assessment has implications for meeting adaptation and mitigation goals (e.g. mitigation targets met through carbon sequestration via afforestation might undermine adaptive capacity if they replace essential food crops).

The methodology is not without caveats. First, there was an issue of combining indicators into the overall dimension-level feasibility. We weighted indicators equally, but future assessments could explore weighting indicators using participatory, expert-elicited or multistakeholder weighting approaches. Second, the three categories of shading may appear simplistic and might mask how feasibility is more along a continuum rather than a triad of high, medium, or low. We purposefully denoted feasibility as shades to use the assessment outcomes as a policy-relevant tool to inform adaptation prioritization and implementation. Third, in the clustering of options, some options were assessed as a group instead of as a single option (e.g. ecosystem restoration and avoided deforestation also included REDD+ and ecosystem-based adaptation) to draw on often overlapping literature while attempting to maintain robustness. In cases where there were particular indicator-level differences between options, these are clarified in the accompanying text.

\section{Findings}

\subsection{Feasibility assessment of adaptation options: four examples}

The feasibility assessment for 23 adaptation options are summarized in Table 2. Darker shades denote higher feasibility (i.e. few barriers to implementation); moderate shading indicates some barriers, and light shading denotes multiple barriers in that particular dimension. To 
Table 2 Feasibility assessment of 23 adaptation options with dark shades signifying the absence of barriers in the feasibility dimension, moderate shading that on average, the dimension signifying some barriers on the option's feasibility, and light shading the presence of barriers. Grey cells denote that the literature was insufficient to make an assessment, while NA signifies that the dimension is not applicable to that adaptation option. The 'context' column captures location or sector-specific characteristics that might change the assessment. For the complete literature base, see Supplementary Material 5

\begin{tabular}{|c|c|c|c|c|c|c|c|c|c|c|}
\hline 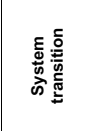 & 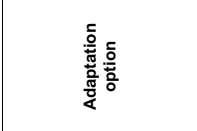 & யँ & 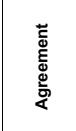 & 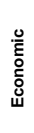 & 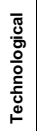 & 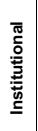 & 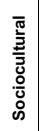 & 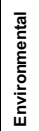 & $\begin{array}{l}\bar{\delta} \\
\frac{0}{n} \\
\frac{0}{0} \\
\overline{0} \\
0 \\
0\end{array}$ & Context \\
\hline \multirow[t]{10}{*}{ Energy } & $\begin{array}{l}\text { Resilient power } \\
\text { infrastructure }\end{array}$ & Medium & High & & & & & & & $\begin{array}{l}\text { Depends on existing power } \\
\text { infrastructure, generation sources, } \\
\text { water requirements }\end{array}$ \\
\hline & Conservation agriculture & Medium & Medium & & & & & & & $\begin{array}{l}\text { Depends on irrigated/rainfed } \\
\text { system, technology, ecosystem, } \\
\text { crop type, farm practices }\end{array}$ \\
\hline & Efficient irrigation & Medium & Medium & & & & & & & $\begin{array}{l}\text { Depends on agriculture system, } \\
\text { technology, institutional and } \\
\text { biophysical contexts }\end{array}$ \\
\hline & $\begin{array}{l}\text { Efficient livestock } \\
\text { systems }\end{array}$ & Limited & High & & & & & & & $\begin{array}{l}\text { Dependent on livestock breeds, } \\
\text { feed practices, and biophysical } \\
\text { context (e.g. carrying capacity) }\end{array}$ \\
\hline & Agroforestry & Medium & High & & & & & & & $\begin{array}{l}\text { Depends on knowledge, financial } \\
\text { support, and market conditions }\end{array}$ \\
\hline & $\begin{array}{l}\text { Community-based } \\
\text { adaptation }\end{array}$ & Medium & High & & & & & & & $\begin{array}{l}\text { Depends on type of intervention, } \\
\text { community buy in, and levels of } \\
\text { participation }\end{array}$ \\
\hline & $\begin{array}{l}\text { Ecosystem restoration \& } \\
\text { avoided deforestation }\end{array}$ & Robust & Medium & & & & & & & $\begin{array}{l}\text { Depends on governance and } \\
\text { financing (especially REDD+ } \\
\text { projects) }\end{array}$ \\
\hline & Biodiversity management & Medium & Medium & & & & & & & $\begin{array}{l}\text { Depends on national priorities, } \\
\text { existing institutions }\end{array}$ \\
\hline & $\begin{array}{l}\text { Coastal defence \& } \\
\text { hardening }\end{array}$ & Robust & Medium & & & & & & & $\begin{array}{l}\text { Depends on locations that require } \\
\text { it as a first adaptation option }\end{array}$ \\
\hline & Sustainable aquaculture & Limited & Medium & & & & & & & $\begin{array}{l}\text { Depends on locations at risk and } \\
\text { socio-cultural context }\end{array}$ \\
\hline \multirow{4}{*}{ 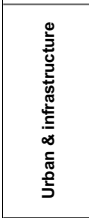 } & $\begin{array}{l}\text { Sustainable land-use \& } \\
\text { urban planning }\end{array}$ & Medium & Medium & & & & & & & $\begin{array}{l}\text { Depends on nature of planning } \\
\text { systems and enforcement } \\
\text { mechanisms }\end{array}$ \\
\hline & $\begin{array}{l}\text { Sustainable water } \\
\text { management }\end{array}$ & Robust & Medium & & & & & & & $\begin{array}{l}\text { Depends on balance between } \\
\text { water supply and rising demand } \\
\text { especially in low-income countries }\end{array}$ \\
\hline & $\begin{array}{l}\text { Green infrastructure \& } \\
\text { ecosystem services }\end{array}$ & Medium & High & & & & & & & $\begin{array}{l}\text { Depends on reconciliation of } \\
\text { urban development with green } \\
\text { infrastructure }\end{array}$ \\
\hline & $\begin{array}{l}\text { Building codes \& } \\
\text { standards }\end{array}$ & Limited & Medium & & & & & & & $\begin{array}{l}\text { Depends on legal, educational, } \\
\text { and enforcement mechanisms }\end{array}$ \\
\hline Industrial & $\begin{array}{l}\text { Intensive industry } \\
\text { infrastructure resilience } \\
\text { and water management }\end{array}$ & Limited & High & & & & & & & $\begin{array}{l}\text { Depends on intensive industry, } \\
\text { existing infrastructure and using or } \\
\text { requiring high demand of water }\end{array}$ \\
\hline \multirow{9}{*}{ 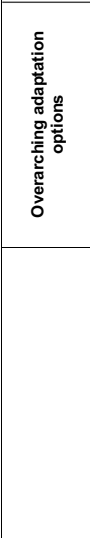 } & $\begin{array}{l}\text { Disaster risk } \\
\text { management }\end{array}$ & Medium & High & & & & & & & $\begin{array}{l}\text { Requires institutional, technical, } \\
\text { and financial capacity in frontline } \\
\text { agencies and government }\end{array}$ \\
\hline & $\begin{array}{l}\text { Risk spreading and } \\
\text { sharing: Social safety } \\
\text { nets }\end{array}$ & Medium & Medium & & & & & & & $\begin{array}{l}\text { Type and mechanism of safety } \\
\text { net, political priorities, institutional } \\
\text { transparency }\end{array}$ \\
\hline & $\begin{array}{l}\text { Risk spreading and } \\
\text { sharing: insurance }\end{array}$ & Medium & Medium & & & & & & & $\begin{array}{l}\text { Requires well developed financial } \\
\text { structures and public } \\
\text { understanding }\end{array}$ \\
\hline & Climate services & Medium & High & & & & & & & $\begin{array}{l}\text { Depends on climate information } \\
\text { availability and usability, local } \\
\text { infrastructure and institutions, }\end{array}$ \\
\hline & & & & & & & & & & national priorities \\
\hline & Indigenous knowledge & Medium & High & & & & & & & $\begin{array}{l}\text { Dependent on recognition of } \\
\text { Indigenous rights, laws, and } \\
\text { governance systems }\end{array}$ \\
\hline & Education and learning & Medium & High & & & & & & & $\begin{array}{l}\text { Existing education system, } \\
\text { systems of knowledge transfer, } \\
\text { funding }\end{array}$ \\
\hline & $\begin{array}{l}\text { Population health and } \\
\text { health system }\end{array}$ & Medium & High & & & & & & NA & $\begin{array}{l}\text { Requires basic health services } \\
\text { and infrastructure }\end{array}$ \\
\hline & Human migration & Medium & Low & & & & & & & $\begin{array}{l}\text { Hazard exposure, political, socio- } \\
\text { cultural acceptability (in } \\
\text { destination), migrant skills and } \\
\text { social networks }\end{array}$ \\
\hline
\end{tabular}

\section{\begin{tabular}{|c|c|c|c|}
\hline No barriers & No effect & Potential barriers & Insufficient literature \\
\hline
\end{tabular}}

Towards the left, columns on 'evidence' and 'agreement' denote the authors' assessment of the depth of the evidence available and whether they were more unanimous (high agreement) or contradictory (low agreement) (Mastrandrea et al. 2010). These assessments of evidence and agreement are at an option scale. Within the feasibility assessment, certain feasibility dimensions are assessed to have 'insufficient literature' (marked grey) which signify particular dimensions having insufficient literature to carry out the assessment of that particular dimension. 
illustrate how the assessment can inform adaptation prioritization and implementation, we discuss four adaptation options in detail (Fig. 1).

\subsubsection{Resilient power infrastructure}

Resilient power infrastructure mainly encompasses infrastructure located in or near coastal areas that are exposed to flood risks and electricity generation systems that require water for cooling, although it also applies to transmission and distribution systems that fail and cause blackouts during extreme weather events. Overall, the use of hybrid systems, islandable microgrids, and storage has high feasibility (Qazi and Young Jr 2014; Canales et al. 2015; Liu et al. 2017). The need for and use of redundancy in power generation processes and infrastructure are reflected in its high technological feasibility (Liu et al. 2017). Although redundancy is usually a characteristic of power system design, the need for increased redundancy is identified with increased climate impacts (Liu et al. 2017). Across different contexts, resilient infrastructure are being implemented successfully, and while efficient use of water and water cooling technologies has been improved, they will be required more frequently in the future especially with changes in water availability and temperature (Eisenack and Stecker 2012; van Vliet et al. 2016). The lack of resilient power infrastructure can exacerbate disruption to power plants and undermine the safety of its personnel and other users, especially during extreme weather events, which could undermine overall economic feasibility. In some locations such as low-lying areas, coastal areas, and areas undergoing increasing water stress, it will no longer be feasible to build power systems or adapt existing ones to increase impacts, for example, in areas projected to experience water scarcity, thermal electricity generation will not remain feasible. To tackle this, increasing power plant efficiency can be a suitable intervention with high economic, social, technological, and institutional feasibility (van Vliet et al. 2016). In other locations, such as those exposed to extreme events, like island nations, coastal areas, and regions in the path of landslides, controllable and islandable microgrids can increase resiliency (Liu et al. 2017).

\subsubsection{Efficient irrigation}

Improving irrigation efficiency is a critical adaptation measure in agriculture systems. Strategies to improve irrigation efficiency include infrastructural strategies such as building large reservoirs or dams, renovating and/or deepening irrigation channels, building on-farm rainwater harvesting structures, lining water bodies to reduce percolation and evaporation losses, and investing in water-saving infrastructure such as sprinkler or drip irrigation (Varela-Ortega et al. 2016; Sikka et al. 2018). Each of these strategies involves costs and benefits, and there is mixed evidence on how to implement efficiency improvements (Fader et al. 2016; Herwehe and Scott 2018). The assessment highlights that while improving irrigation efficiency is technically feasible and has ecological benefits (Pfeiffer and Lin 2014; Fishman et al. 2015), its overall feasibility is regionally differentiated. For example, improving irrigation efficiency in India (e.g. through drip or sprinkler irrigation technologies) is enabled by policy incentives but blocked by inadequate local institutional and administrative capacities, whereas in Kenya, devolution of water management to hybrid formal-informal institutions at the local scale has improved social and institutional feasibility (Ziervogel et al. 2019). Overall, however, the feasibility of improving irrigation efficiency is constrained by issues of replicability across scale and sustainability over time (Burney and Naylor 2012), institutional barriers, and inadequate market linkages (Pittock et al. 2017). 


\subsubsection{Green infrastructure and ecosystem services}

Green infrastructure is a critical adaptation strategy in urban areas and can promote stewardship of urban ecosystems, provide recreational and health co-benefits, promote social cohesion, and improve overall quality of life (Elmqvist et al. 2015; McPhearson et al. 2015; Li et al. 2017; Collas et al. 2017). The feasibility assessment indicates that apart from being ecologically feasible, investing in green infrastructure and ecosystem services yields multiple social and economic benefits (Elmqvist et al. 2015; Li et al. 2017; Collas et al. 2017). There is limited knowledge on how best to reconcile urban development with green infrastructure and ecosystem services, with some examples of community-based adaptation and ecosystem-based adaptation demonstrating transformative potential (Archer et al. 2014). In recent decades, political acceptability for green infrastructure has increased; for example, city planners are increasingly seeing storm-water management as a flood prevention tool that supports other much-needed ecosystem services (e.g. groundwater recharge and better water quality)(Costa et al. 2016). However, local governance and institutional gaps are critical barriers to effective management of ecosystem services such as with increasing evidence on fragmented governance, lack of coordination between different agencies, focus on technocratic approaches, and lack of specific management capacities.

Urban adaptation interventions are sharply shaped by local governance and institutional structures with political factors often leading to unjust outcomes (Fainstein 2015; Anguelovski et al. 2016; Goh 2019), particularly for those who are the most vulnerable (Shi et al. 2016) (Goh 2019). The feasibility of urban green infrastructure is strongly differentiated across cities: e.g. New York City reports strong actions on rooftop and land-based urban agriculture (Ackerman et al. 2014) due to enabling municipal policies and bottom-up action from community groups. On the other hand, the feasibility of urban farming in rapidly developing cities such as in Ghana remain low due to inadequate institutional support, perverse land policies, and poor financial incentives (Ayambire et al. 2019).

\subsubsection{Indigenous knowledge}

IK systems underpin the adaptive capacity of indigenous communities in many regions, through the diversity and flexibility of indigenous agroecological systems, collective social memory, repository of accumulated experience, and from social networks essential for disaster response and recovery (Pearce et al. 2015; Hiwasaki et al. 2015; Mapfumo et al. 2016; Sherman et al. 2016; Ingty 2017), providing mitigation co-benefits (Altieri and Nicholls 2017; Russell-Smith et al. 2017) and assisting in transitions to broader sustainable development (Magni 2017; Thornton and Comberti 2017). Reflecting this, adaptations based on IK scored high on sociocultural, environmental, and geophysical feasibility dimensions, including integration of IK into resource management systems and school curricula, digital storytelling and film-making, cultural events, web-based knowledge banks, radio dramas, and weather forecasting (Cunsolo Willox et al. 2013; Chambers et al. 2017; Inamara and Thomas 2017). Institutional feasibility, however, can have a potential blocking role, reflecting limited recognition of indigenous land rights in many regions, disempowerment, and top-down decisionmaking contexts in which indigenous epistemologies and worldviews are not respected (Ford 2012; Hooli 2016; Mistry and Berardi 2016). Moreover, IK systems are being weakened and threatened by acculturation, rapid environmental changes, colonization, and social change 
(Ford 2012; Nakashima et al. 2012; McNamara and Prasad 2014; Fernández-Llamazares et al. 2015), challenging institutional, economic, and technological feasibility.

The feasibility of using IK to adapt is differentiated across contexts. In some locations, the unprecedented rates of change are making some components of IK less reliable (Fernández-Llamazares et al. 2015; Peppler 2017), while in other regions, rapid change has resulted in adaptive learning (Ford et al. 2015; Huntington et al. 2017). For some populations, sociocultural changes have resulted in maladaptive responses such as in urban Tuvalu where certain food practices have been documented to prioritize the consumption of cheap, nutrient-poor food (Mccubbin et al. 2017). In other regions, sociocultural changes have resulted in new 'hybrid' knowledge systems and practices, with such dynamics observed to result in significant adaptive capacity (Orlove et al. 2010; Leonard et al. 2013; Reyes-Garcia et al. 2014).

These examples demonstrate how the feasibility assessment provides a menu of options and the state of current knowledge on how feasible they are from an economic, technological, institutional, sociocultural, environmental, and geophysical standpoint (Fig. 2). Further, they showcase that in different geographies, the feasibility of an adaptation option might change, thereby underscoring the importance of context on adaptation feasibility.

\subsection{Adaptation and mitigation synergies and trade-offs}

Implementing a particular adaptation option can have synergies and/or trade-offs with mitigation and vice versa (Kongsager et al. 2016; Di Gregorio et al. 2017; Thornton and Comberti 2017). When examined through the lens of system transitions, this has implications for meeting adaptation and mitigation goals (e.g. mitigation targets met through carbon sequestration via afforestation might undermine adaptive capacity if they replace essential food crops). To understand how synergies and trade-offs between mitigation and adaptation measures play out, we assessed possible positive impacts (synergies) and negative impacts (trade-offs) of adaptation options for mitigation (four illustrative examples are presented in Supplementary Information 4).

The synergies and trade-off analysis highlight several important points. First, there is a growing literature around the mitigation implications of adaptation options that identify key considerations for adaptation practice. However, an understanding of synergies and trade-offs of mitigation actions on adaptation remains nascent. Second, investing in options that have synergies can create win-win situations for adaptation and mitigation (e.g. green infrastructure options can reduce energy requirements for cooling while reducing heat-related health stress), thus accelerating climate action. Third, by identifying trade-offs, negative outcomes can be minimized ex ante (e.g. switching to irrigation technologies that improve water efficiency, but use of diesel has long-term mitigation trade-offs). Fourth, focussing on synergies and tradeoffs can pre-empt potentially maladaptive and mal-mitigative strategies.

\subsection{Directions for future adaptation research}

Through the feasibility assessment process, several knowledge gaps emerged which are areas ripe for future research. Overall, there is low evidence on cost-effectiveness of different adaptation options and of the required speed and scale of adaptation implementation. There was limited literature examining what different climate scenarios mean for adaptation success. A growing body of literature is furthering conceptual thinking around maladaptation and 

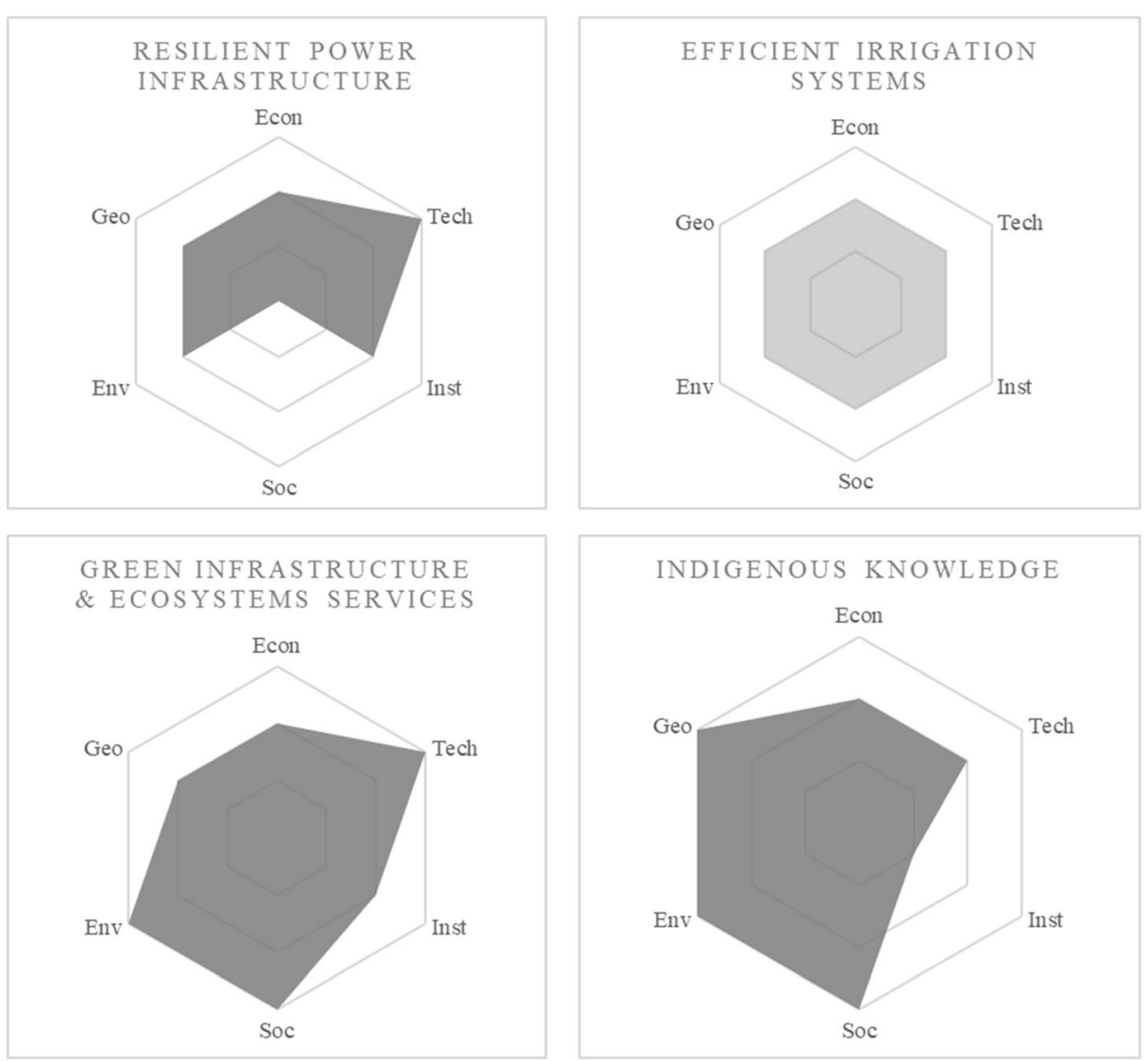

Fig. 2 Feasibility assessment of select adaptation options. The progression from inner to outer hexagons presents low, medium, and high feasibility. Thus, 'resilient power infrastructure' scores 'high' on the technological feasibility dimension but low on the sociocultural feasibility dimension. Darker colours suggest higher confidence (i.e. there is more evidence with higher consensus)

transformational adaptation (Colloff et al. 2016; Warner and Kuzdas 2017; Nightingale et al. 2019; Gajjar et al. 2019), but there remains limited empirical evidence on how these play out in different contexts.

The feasibility assessment identified key gaps on specific adaptation options. For example, under energy system transitions, there is relatively little progress on individual adaptation options since AR5, negligible evidence on sociocultural acceptability of adaptation options, and a lack of regional research on their implementation. In land and ecosystem transitions, longitudinal, regional studies assessing the impacts of certain adaptation options such as conservation agriculture and shifting to efficient livestock systems were few. There was limited research examining sociocultural feasibility of certain options such as efficient irrigation, coastal defence and hardening, agroforestry, and biodiversity management.

Certain feasibility indicators such as political acceptability, legal and regulatory feasibility, and transparency and accountability potential had limited evidence across most adaptation options (although there were some broad examples such as Patterson et al. 2018). Under urban and infrastructure system transitions, more knowledge is needed on the political economy of 
adaptation and the impact of adaptation interventions on socio-economic and other types of inequality (though we note a growing evidence base here, e.g. Ziervogel et al. 2017). Uncertainties emanate from the lack of knowledge on the integration of climate adaptation and mitigation, disaster risk management, and poverty alleviation. Also, more evidence is needed on emerging hotspots such as peri-urban areas in the Global South. Overarching adaptation options, though drawing on a wide body of multidisciplinary literature, had gaps such as limited evidence on scaling up and cost-effectiveness. We would specifically like to highlight the small but growing literature on human migration as an adaptation strategy which is emerging and tended to have low agreement internally, making the feasibility assessment difficult given the present state of knowledge.

\section{Discussion}

In this paper, we present a rigorous and transparent process to assess the feasibility of adaptation options globally, anchoring them around four system transitions. Reflecting on the process used in the IPCC Special Report on $1.5^{\circ} \mathrm{C}$ (de Coninck et al. 2018), we lay out a multidimensional feasibility assessment framework (Fig. 1) along with its caveats. We use four illustrative examples of adaptation options (Fig. 2) to highlight how such a framework can facilitate robust, transparent assessment which synthesizes the growing evidence base in a policy-facing manner. This is particularly relevant as the negotiations around the Paris Climate Agreement reach a critical phase and climate policy starts shifting focus to implementation and regulation of commitments and outcomes (e.g. through the Global Stocktake).

The feasibility assessment framework presented in this paper lays out a process of synthesizing large bodies of climate-relevant literature to produce a menu of options that policymakers can potentially use to move towards implementation. It also overcomes the characteristic challenge of adaptation research of synthesizing numerous local studies to make policyrelevant contributions to help define global adaptation priorities (Biesbroek et al. 2018a). This framework could provide an initial scaffolding for similar assessments at regional, national, and local levels where data and peer-reviewed literature is available. In locations where literature is sparse around particular options, this frame has considerable value in helping define knowledge and research gaps that if filled could bolster climate action. Ideally, we expect the feasibility assessment to be supplemented by text on 'enabling conditions' (de Coninck et al. 2018; Waisman et al. 2019), i.e. specific financial, institutional, technological, and behavioural measures that enable the implementation and uptake of a feasible adaptation option.

The output of the feasibility assessment (Table 2) can at first glance appear generic and not amenable to informing policymaking. However, the feasibility table is a snapshot of the entire feasibility assessment and presented as the first layer in a pyramid of information. Meant to be policy-facing, the table is a visual aimed at global and national policymakers as well as nongovernmental adaptation decision-makers and practitioners to highlight that there are several differently feasible adaptation options across systems. The last column in the table emphasizes how context plays a critical role in option-level feasibility with these contextual factors (from the literature) highlighted. In the text accompanying this table, the feasibility of each option is detailed through examples of how certain options are more or less feasible than others in certain regions/governance regimes/sociocultural contexts.

We envision the results presented in the paper as step 1 of a longer, layered process. In subsequent steps, we hope to have countries/sectors/subnational entities test and revise the 
assessment framework to suite their contexts. Further, the feasibility assessment framework is aimed at developing better frameworks for assessment by the IPCC and other similar initiatives such as the IPBES. We find the reported framework is an improvement over AR5 assessments which tended to mention some examples of adaptation action but did not assess adaptation feasibility and thus provided a list of options without any indication of feasibility.

In the introduction, we had identified key concerns with current global adaptation assessments. In Table 3, we revisit these critiques and highlight how the feasibility assessment framework we present addresses these challenges, albeit to different degrees. The feasibility assessment framework takes a systems approach that overcomes some challenges of synthesizing adaptation research (e.g. dispersed case studies, non-transparent ways of monitoring/ tracking feasibility). Other aspects such as making adaptation synthesis policy relevant and drawing on more plural knowledge systems were partially addressed.

In particular, the feasibility assessment framework also paved the way for an analysis of adaptation and mitigation synergies and trade-offs (Supplementary Information 4), which highlighted several important points. First, investing in options that have synergies can create win-win situations for adaptation and mitigation (e.g. green infrastructure options can reduce energy requirements for cooling while reducing heat-related health stress), thus accelerating climate action. Second, by identifying trade-offs, negative outcomes can be minimized ex ante (e.g. switching to irrigation technologies that improve water efficiency, but use of diesel has long-term, avoidable mitigation trade-offs). Third, focussing on synergies and trade-offs can pre-empt potentially maladaptive strategies and inform targeted adaptation funding and prioritization. However, the synergies and trade-off analysis presented in Section 3.2 were qualitative and only assessed whether there was a positive or negative relationship between an adaptation option and carbon emissions. The analysis did not examine the degree to which the synergy or trade-off played out, mainly because quantifying mitigation synergies and tradeoffs was difficult due to inadequate and uneven literature.

The framework is of course not without limitations. In the future work, we aim to better capture the important role played by inequality, power, and differential agency in mediating the feasibility and implementation of adaptation options. Reporting biases are an inevitable challenge facing literature-based analyses, and while our approach makes explicit what literature was used, the assessment carries with it reporting biases present in the literature (i.e. certain options have more peer-reviewed evidence, and certain regions such as Central and West Asia are heavily underrepresented). Also, more traditional options that have been implemented over longer periods are likely to experience more barriers than more novel, recent, or untested options. We find that the assessment framework deals with these biases through its focus on identifying knowledge gaps, both regionally and option-wise. While newer options (e.g. climate smart agriculture) did have a smaller literature base, the assessment allowed us to identify this gap and highlights where the research community can focus its attention. Thus, borrowing from traditions of systematic reviews (Berrang-Ford et al. 2011), the assessment framework focusses attention on filling gaps.

This assessment framework is conceptualized as a first step towards building comprehensive adaptation datasets that span all geographies and sectors. This could be done by creating national and/or subnational databases and conducting feasibility assessments either for specific system transitions or certain sectors. The assessment exercise reported here also calls for an intense effort within the climate science community to address questions of the costs of various 
Table 3 Ways in which the feasibility assessment framework addresses common critiques of studies assessing adaptation at a global scale

Critiques of current assessments of adaptation How the feasibility assessment framework addresses this options

Biased towards peer-reviewed literature and Partially addressed. The feasibility assessment drew evidence discounts practitioner knowledge from peer-reviewed literature with a deliberate effort to include grey literature. The current assessment did not assess IK directly but reviewed peer-reviewed articles that document aspects of IK

Top-down accounts that obfuscate contextual Mostly addressed. The assessment was at a global scale covering issues four systems and within them, numerous sectors. However, recognizing the contextual nature of adaptation feasibility, the global assessment was supplemented by attention to regional differences - for example, in the discussion on sustainable livestock systems, differences in feasibility of adaptation between East African pastoralists and North American ranchers were highlighted

Lacking transparency in selecting and appraising the literature

Completely addressed. The feasibility assessment follows a clear line of sight where 23 adaptation options were assessed based on 603 unique references. Each dimension-level score of high, medium, and low is substantiated by supporting evidence

Assessments typically on single options, lack Completely addressed. Drawing on recent advances in of systems approach sustainability and adaptation literature, the feasibility framework takes a system transition approach and did not focus on one adaptation option but multiple options within a system (e.g. conservation agriculture, sustainable irrigation, sustainable livestock, food waste management under land, and ecosystem transitions)

Lack of discussion of synergies and trade-offs Completely addressed. The assessment framework also assessed between options mitigation options within each system, thereby allowing for an analysis of synergies and trade-offs between options at a system level (e.g. Section 3.2)

Gaps in assessments

Completely addressed. The feasibility assessment was particularly robust in identifying gaps in knowledge (Section 3.3) by assessing particular dimensions on which specific adaptation options had insufficient or no evidence

Inadequate policy relevance

Mostly addressed. The feasibility assessment, conducted at an option level, is explicitly policy-facing since it provides decision-makers with a menu of options to choose from and indicates which dimensions block a certain option's feasibility, thereby signalling where fund allocation can help increase feasibility. For example, green infrastructure emerges as a feasible adaptation option in urban system transitions but scores relatively low on institutional feasibility. This can signal to a policymaker that investing in institutions and policy measures to support green infrastructure can make it a highly feasible option

options, the scale and speed of deployment of these options, and the conjoint feasibility of complementary adaptation and mitigation options. Given the multiple policy challenges asking for 'triple-win' solution sets that seek to bring together sustainable development, climate change action, and disaster risk reduction, we see the feasibility assessment framework presented here as a step towards assessing and synthesizing existing knowledge to inform such policy choices. 
Open Access This article is licensed under a Creative Commons Attribution 4.0 International License, which permits use, sharing, adaptation, distribution and reproduction in any medium or format, as long as you give appropriate credit to the original author(s) and the source, provide a link to the Creative Commons licence, and indicate if changes were made. The images or other third party material in this article are included in the article's Creative Commons licence, unless indicated otherwise in a credit line to the material. If material is not included in the article's Creative Commons licence and your intended use is not permitted by statutory regulation or exceeds the permitted use, you will need to obtain permission directly from the copyright holder. To view a copy of this licence, visit http://creativecommons.org/licenses/by/4.0/.

\section{References}

Abid M, Schneider UA, Scheffran J (2016) Adaptation to climate change and its impacts on food productivity and crop income: perspectives of farmers in rural Pakistan. J Rural Stud 47:254-266

Ackerman K, Conard M, Culligan P et al (2014) Sustainable food systems for future cities: the potential of urban agriculture. Econ Soc Rev (Irel) 45:189-206

Alfieri L, Feyen L, Di Baldassarre G (2016) Increasing flood risk under climate change: a pan-European assessment of the benefits of four adaptation strategies. Clim Chang 136:507-521

Allen MR, Dube OP, Solecki W, et al (2018) Framing and context. In: global warming of 1.5 C an IPCC special report

Altieri MA, Nicholls CI (2017) The adaptation and mitigation potential of traditional agriculture in a changing climate. Clim Chang 140:33-45. https://doi.org/10.1007/s10584-013-0909-y

Anguelovski I, Shi L, Chu E et al (2016) Equity impacts of urban land use planning for climate adaptation. J Plan Educ Res 36:333-348. https://doi.org/10.1177/0739456X16645166

Araos M, Ford J, Berrang-Ford L et al (2017) Climate change adaptation planning for Global South megacities: the case of Dhaka. J Environ Policy Plan 19:682-696. https://doi.org/10.1080/1523908X.2016.1264873

Archer D, Almansi F, DiGregorio M et al (2014) Moving towards inclusive urban adaptation: approaches to integrating community-based adaptation to climate change at city and national scale. Clim Dev 6:345-356. https://doi.org/10.1080/17565529.2014.918868

Ayambire RA, Amponsah O, Peprah C, Takyi SA (2019) A review of practices for sustaining urban and periurban agriculture: implications for land use planning in rapidly urbanising Ghanaian cities. Land Use Policy 84:260-277. https://doi.org/10.1016/j.landusepol.2019.03.004

Barnett J, Evans LS, Gross C et al (2015) From barriers to limits to climate change adaptation: path dependency and the speed of change. Ecol Soc:20. https://doi.org/10.5751/ES-07698-200305

Bassett TJ, Fogelman C (2013) Deja vu or something new? The adaptation concept in the climate change literature. Geoforum 48:42-53. https://doi.org/10.1016/j.geoforum.2013.04.010

Beck S (2011) Moving beyond the linear model of expertise? IPCC and the test of adaptation. Reg Environ Chang 11:297-306. https://doi.org/10.1007/s10113-010-0136-2

Berbés-Blázquez M, Mitchell CL, Burch SL, Wandel J (2017) Understanding climate change and resilience: assessing strengths and opportunities for adaptation in the Global South. Clim Chang 141:227-241. https://doi.org/10.1007/s10584-017-1897-0

Berrang-Ford L, Ford JD, Paterson J (2011) Are we adapting to climate change? Glob Environ Chang 21:25-33. https://oi.org/10.1016/j.gloenvcha.2010.09.012

Berrang-Ford L, Pearce T, Ford JD (2015) Systematic review approaches for climate change adaptation research. Reg Environ Chang 15:755-769. https://doi.org/10.1007/s10113-014-0708-7

Biesbroek GR, Klostermann JEM, Termeer CJAM, Kabat P (2013) On the nature of barriers to climate change adaptation. Reg Environ Chang 13:1119-1129. https://doi.org/10.1007/s10113-013-0421-y

Biesbroek GR, Termeer CJAM, Klostermann JEM, Kabat P (2014a) Analytical lenses on barriers in the governance of climate change adaptation. Mitig Adapt Strateg Glob Chang 19:1011-1032. https://oi. org/10.1007/s11027-013-9457-z

Biesbroek GR, Termeer CJAM, Klostermann JEM, Kabat P (2014b) Rethinking barriers to adaptation: mechanism-based explanation of impasses in the governance of an innovative adaptation measure. Glob Environ Chang 26:108-118. https://doi.org/10.1016/j.gloenvcha.2014.04.004

Biesbroek R, Dupuis J, Jordan A et al (2015) Opening up the black box of adaptation decision-making. Nat Clim Chang 5:493-494. https://doi.org/10.1038/nclimate2615

Biesbroek R, Berrang-Ford L, Ford JD et al (2018a) Data, concepts and methods for large- n comparative climate change adaptation policy research: a systematic literature review. Wiley Interdiscip Rev Clim Chang:e548. https://doi.org/10.1002/wcc.548 
Biesbroek R, Lesnikowski A, Ford JD et al (2018b) Do administrative traditions matter for climate change adaptation policy? A comparative analysis of 32 high-income countries. Rev Policy Res 35:881-906. https://doi.org/10.1111/ropr.12309

Brooks N, Anderson S, Burton I, et al (2013) An operational framework for tracking adaptation and measuring development (TAMD)

Burney JA, Naylor RL (2012) Smallholder irrigation as a poverty alleviation tool in sub-Saharan Africa. World Dev 40:110-123. https://doi.org/10.1016/j.worlddev.2011.05.007

Canales FA, Beluco A, Mendes CAB (2015) A comparative study of a wind hydro hybrid system with water storage capacity: conventional reservoir or pumped storage plant? J Energy Storage 4:96-105. https://oi. org/10.1016/j.est.2015.09.007

Chakrabarty S, Boksh FIMM, Chakraborty A (2013) Economic viability of biogas and green self-employment opportunities. Renew Sust Energ Rev 28:757-766

Chambers LE, Plotz RD, Dossis T et al (2017) A database for traditional knowledge of weather and climate in the Pacific. Meteorol Appl 24:491-502. https://doi.org/10.1002/met.1648

Champalle C, Ford JD, Sherman M (2015) Prioritizing climate change adaptations in Canadian Arctic communities. Sustainability 7:9268-9292. https://doi.org/10.3390/su7079268

Chun JA, Li S, Wang Q et al (2016) Assessing rice productivity and adaptation strategies for Southeast Asia under climate change through multi-scale crop modeling. Agric Syst 143:14-21

Collas L, Green RE, Ross A et al (2017) Urban development, land sharing and land sparing: the importance of considering restoration. J Appl Ecol 54:1865-1873. https://doi.org/10.1111/1365-2664.12908

Colloff MJ, Martín-López B, Lavorel S et al (2016) An integrative research framework for enabling transformative adaptation. Environ Sci Pol 10. https://doi.org/10.1016/j.envsci.2016.11.007

Costa D, Burlando P, Priadi C (2016) The importance of integrated solutions to flooding and water quality problems in the tropical megacity of Jakarta. Sustain Cities Soc 20:199-209. https://doi.org/10.1016/j. scs.2015.09.009

Cunsolo Willox A, Harper SL, Edge VL (2013) Storytelling in a digital age: digital storytelling as an emerging narrative method for preserving and promoting indigenous oral wisdom. Qual Res 13:127-147. https://doi. org/10.1177/1468794112446105

Dalton G, Allan G, Beaumont N et al (2015) Economic and socio-economic assessment methods for ocean renewable energy: public and private perspectives. Renew Sust Energ Rev 45:850-878

de Coninck H, Revi A, Babiker M, et al (2018) Strengthening and implementing the global response. In: global warming of $1.5 \mathrm{C}$ an IPCC special report. Intergovernmental panel on climate change

Di Gregorio M, Nurrochmat DR, Paavola J et al (2017) Climate policy integration in the land use sector: mitigation, adaptation and sustainable development linkages. Environ Sci Pol 67:35-43. https://doi. org/10.1016/J.ENVSCI.2016.11.004

Eisenack K, Stecker R (2012) A framework for analyzing climate change adaptations as actions. Mitig Adapt Strateg Glob Chang 17:243-260. https://doi.org/10.1007/s11027-011-9323-9

Eisenack K, Moser SC, Hoffmann E et al (2014) Explaining and overcoming barriers to climate change adaptation. Nat Clim Chang 4:867-872. https://doi.org/10.1038/nclimate2350

Elmqvist T, Setälä H, Handel SN et al (2015) Benefits of restoring ecosystem services in urban areas. Curr Opin Environ Sustain 14:101-108. https://doi.org/10.1016/j.cosust.2015.05.001

Evans LS, Hicks CC, Adger N et al (2016) Structural and psycho-social limits to climate change adaptation in the great barrier reef region. PLoS One 11:1-17. https://doi.org/10.1371/journal.pone.0150575

Fader M, Shi S, von Bloh W et al (2016) Mediterranean irrigation under climate change: more efficient irrigation needed to compensate for increases in irrigation water requirements. Hydrol Earth Syst Sci 20:953-973. https://doi.org/10.5194/hess-20-953-2016

Fainstein S (2015) Resilience and justice. Int J Urban Reg Res 39:157-167. https://doi.org/10.1111/14682427.12186

Fazey I, Wise RM, Lyon C et al (2016) Past and future adaptation pathways. Clim Dev 8:26-44. https://doi. org/10.1080/17565529.2014.989192

Fernández-Llamazares Á, Díaz-Reviriego I, Luz AC et al (2015) Rapid ecosystem change challenges the adaptive capacity of local environmental knowledge. Glob Environ Chang 31:272-284. https://doi. org/10.1016/j.gloenvcha.2015.02.001

Fisher S, Dinshaw A, Mcgray H et al (2015) Evaluating climate change adaptation: learning from methods in international development. New Dir Eval 2015:13-35. https://doi.org/10.1002/ev.20128

Fishman R, Devineni N, Raman S (2015) Can improved agricultural water use efficiency save India's groundwater? Environ Res Lett 10:084022. https://doi.org/10.1088/1748-9326/10/8/084022

Ford JD (2012) Indigenous health and climate change. Am J Public Health 102:1260-1266. https://doi. org/10.2105/AJPH.2012.300752 
Ford JD, King D (2015) A framework for examining adaptation readiness. Mitig Adapt Strateg Glob Chang 20: 505-526. https://doi.org/10.1007/s11027-013-9505-8

Ford JD, Pearce T (2010) What we know, do not know, and need to know about climate change vulnerability in the western Canadian Arctic: a systematic literature review. Environ Res Lett. https://doi.org/10.1088/17489326/5/1/014008

Ford JD, Berrang-Ford L, Lesnikowski A et al (2013) How to track adaptation to climate change: a typology of approaches for national-level application. Ecol Soc 18:art40. https://doi.org/10.5751/ES-05732-180340

Ford JD, McDowell G, Pearce T (2015) The adaptation challenge in the Arctic. Nat Clim Chang 5:1046-1053. https://doi.org/10.1038/nclimate2723

Ford JD, Cameron L, Rubis J et al (2016) Including indigenous knowledge and experience in IPCC assessment reports. Nat Clim Chang 6:349-353. https://oi.org/10.1038/nclimate2954

Ford JD, Labbé J, Flynn M, Araos M (2017) Readiness for climate change adaptation in the Arctic: a case study from Nunavut, Canada. Clim Chang 145:85-100. https://doi.org/10.1007/s10584-017-2071-4

Gajjar SP, Singh C, Deshpande T (2019) Tracing back to move ahead: a review of development pathways that constrain adaptation futures. Clim Dev 11:223-237. https://doi.org/10.1080/17565529.2018.1442793

Gillard R, Gouldson A, Paavola J, Van Alstine J (2016) Transformational responses to climate change: beyond a systems perspective of social change in mitigation and adaptation. Wiley Interdiscip Rev Clim Chang 7: 251-265. https://doi.org/10.1002/wcc.384

Goh K (2019) Flows in formation: the global-urban networks of climate change adaptation. Urban Stud. https://doi.org/10.1177/0042098018807306

Gupta J (2016) Climate change governance: history, future, and triple-loop learning? Wiley Interdiscip Rev Clim Chang 7:192-210. https://doi.org/10.1002/wcc.388

Harrison PA, Holman IP, Berry PM (2015) Assessing cross-sectoral climate change impacts, vulnerability and adaptation: an introduction to the CLIMSAVE project. Clim Chang 128:153-167. https://doi.org/10.1007 /s10584-015-1324-3

Harvey CA, Chacón M, Donatti CI et al (2014) Climate-smart landscapes: opportunities and challenges for integrating adaptation and mitigation in tropical agriculture. Conserv Lett 7:77-90. https://doi.org/10.1111 /conl.12066

Haunschild R, Bornmann L, Marx W (2016) Climate change research in view of bibliometrics. PLoS One 11: e0160393. https://doi.org/10.1371/journal.pone.0160393

Henstra D (2016) The tools of climate adaptation policy: analysing instruments and instrument selection. Clim Policy 16:496-521. https://doi.org/10.1080/14693062.2015.1015946

Herwehe L, Scott CA (2018) Drought adaptation and development: small-scale irrigated agriculture in Northeast Brazil. Clim Dev 10:337-346. https://doi.org/10.1080/17565529.2017.1301862

Hiwasaki L, Luna E, Syamsidik MJA (2015) Local and indigenous knowledge on climate-related hazards of coastal and small island communities in Southeast Asia. Clim Chang 128:35-56. https://doi.org/10.1007 /s10584-014-1288-8

Hjerpe M, Storbjörk S, Alberth J (2015) “There is nothing political in it": triggers of local political leaders' engagement in climate adaptation. Local Environ 20:855-873. https://doi.org/10.1080 $/ 13549839.2013 .872092$

Hooli LJ (2016) Resilience of the poorest: coping strategies and indigenous knowledge of living with the floods in Northern Namibia. Reg Environ Chang 16:695-707. https://doi.org/10.1007/s10113-015-0782-5

Howarth C, Viner D, Dessai S et al (2017) Enhancing the contribution and role of practitioner knowledge in the intergovernmental panel on climate change (IPCC) working group (WG) II process: insights from UK workshops. Clim Serv 5:3-10. https://doi.org/10.1016/j.cliser.2017.04.003

Huntington HP, Quakenbush LT, Nelson M (2017) Evaluating the effects of climate change on indigenous marine mammal hunting in northern and western Alaska using traditional knowledge. Front Mar Sci 4:319

Inamara A, Thomas V (2017) Pacific climate change adaptation: the use of participatory media to promote indigenous knowledge. Pacific Journal Rev 23:113-132. https://doi.org/10.24135/pjr.v23i1.210

Ingty T (2017) High mountain communities and climate change: adaptation, traditional ecological knowledge, and institutions. Clim Chang 145:41-55. https://doi.org/10.1007/s10584-017-2080-3

IPCC (2018) Annex I: glossary. In: Matthews R (ed) global warming of $1.5^{\circ} \mathrm{C}$

Jacobson MZ, Howarth RW, Delucchi MA et al (2013) Examining the feasibility of converting New York State's all-purpose energy infrastructure to one using wind, water, and sunlight. Energy Policy 57:585-601. https://doi.org/10.1016/j.enpol.2013.02.036

Jordan AJ, Huitema D, Hildén M et al (2015) Emergence of polycentric climate governance and its future prospects. Nat Clim Chang 5:977-982

Klein RJT, Midgley GF, Preston BL et al (2014) Adaptation opportunities, constraints, and limits. In: Field CB, Barros VR, Dokken DJ et al (eds) Climate change 2014: impacts, adaptation, and vulnerability. Cambridge University Press, Cambridge, pp 899-943 
Kongsager R, Locatelli B, Chazarin F (2016) Addressing climate change mitigation and adaptation together: a global assessment of agriculture and forestry projects. Environ Manag 57:271-282. https://doi.org/10.1007 /s00267-015-0605-y

Leonard S, Parsons M, Olawsky K, Kofod F (2013) The role of culture and traditional knowledge in climate change adaptation: insights from East Kimberley, Australia. Glob Environ Chang 23:623-632. https://oi. org/10.1016/j.gloenvcha.2013.02.012

Li F, Liu X, Zhang X et al (2017) Urban ecological infrastructure: an integrated network for ecosystem services and sustainable urban systems. J Clean Prod 163:S12-S18. https://doi.org/10.1016/j.jclepro.2016.02.079

Liu X, Shahidehpour M, Li Z et al (2017) Microgrids for enhancing the power grid resilience in extreme conditions. IEEE Trans Smart Grid 8:589-597. https://doi.org/10.1109/TSG.2016.2579999

Livingston JE, Lövbrand E, Alkan Olsson J (2018) From climates multiple to climate singular: maintaining policy-relevance in the IPCC synthesis report. Environ Sci Pol 90:83-90. https://doi.org/10.1016/J. ENVSCI.2018.10.003

Locatelli B, Pavageau C, Pramova E, Di Gregorio M (2015) Integrating climate change mitigation and adaptation in agriculture and forestry: opportunities and trade-offs. Wiley Interdiscip Rev Clim Chang 6:585-598. https://doi.org/10.1002/wcc.357

Loftus PJ, Cohen AM, Long JCS, Jenkins JD (2015) A critical review of global decarbonization scenarios: what do they tell us about feasibility? Wiley Interdiscip Rev Clim Chang 6:93-112. https://doi.org/10.1002 /wcc. 324

Magnan AK, Schipper ELF, Burkett M et al (2016) Addressing the risk of maladaptation to climate change. Wiley Interdiscip Rev Clim Chang 7:646-665. https://doi.org/10.1002/wcc.409

Magni G (2017) Indigenous knowledge and implications for the sustainable development agenda. Eur J Educ 52: 437-447. https://doi.org/10.1111/ejed.12238

Mapfumo P, Mtambanengwe F, Chikowo R (2016) Building on indigenous knowledge to strengthen the capacity of smallholder farming communities to adapt to climate change and variability in southern Africa. Clim Dev 8:72-82. https://doi.org/10.1080/17565529.2014.998604

Mastrandrea MD, Field CB, Stocker TF, et al (2010) Guidance note for lead authors of the IPCC fifth assessment report on consistent treatment of uncertainties

Masud MM, Azam MN, Mohiuddin M et al (2017) Adaptation barriers and strategies towards climate change: challenges in the agricultural sector. J Clean Prod 156:698-706. https://doi.org/10.1016/j. jclepro.2017.04.060

Mbow C, Smith P, Skole D et al (2014) Achieving mitigation and adaptation to climate change through sustainable agroforestry practices in Africa. Curr Opin Environ Sustain 6:8-14. https://doi.org/10.1016/j. cosust.2013.09.002

Mccubbin SG, Pearce T, Ford JD, Smit B (2017) Social-ecological change and implications for food security in Funafuti, Tuvalu. Ecol Soc 22:53-65. https://doi.org/10.5751/ES-09129-220153

McEvoy D, Fünfgeld H, Bosomworth K (2013) Resilience and climate change adaptation: the importance of framing. Plan Pract Res 28:280-293. https://doi.org/10.1080/02697459.2013.787710

McKinnon MC (2015) Map the evidence. Nature 528:185-187. https://doi.org/10.1038/529466b

McNamara KE, Prasad SS (2014) Coping with extreme weather: communities in Fiji and Vanuatu share their experiences and knowledge. Clim Chang 123:121-132. https://doi.org/10.1007/s10584-013-1047-2

McPhearson T, Andersson E, Elmqvist T, Frantzeskaki N (2015) Resilience of and through urban ecosystem services. Ecosyst Serv 12:152-156

Minx JC, Callaghan M, Lamb WF et al (2017) Learning about climate change solutions in the IPCC and beyond. Environ Sci Pol 77:252-259. https://doi.org/10.1016/j.envsci.2017.05.014

Mistry J, Berardi A (2016) Bridging indigenous and scientific knowledge. Science (80-. ) 352:1274-1275

Moser SC, Ekstrom JA (2010) A framework to diagnose barriers to climate change adaptation. Proc Natl Acad Sci U S A 107:22026-22031. https://doi.org/10.1073/pnas.1007887107

Nakashima DJ, Galloway McLean K, Thulstrup HD et al (2012) Weathering uncertainty: traditional knowledge for climate change assessment and adaptation. UNESCO, Paris, France and UNU, Darwin, Australia

Nelson DR, Adger WN, Brown K (2007) Adaptation to environmental change: contributions of a resilience framework. Annu Rev Environ Resour 32:395-419. https://doi.org/10.1146/annurev. energy.32.051807.090348

Nightingale AJ, Eriksen S, Taylor M et al (2019) Beyond technical fixes: climate solutions and the great derangement. Clim Dev:1-10. https://doi.org/10.1080/17565529.2019.1624495

Noble I, Huq S, Anokhin Y et al (2014) Adaptation needs and options. In: Field CB, Barros VR, Dokken DJ et al (eds) Climate change 2014: impacts, adaptation, and vulnerability. Cambridge University Press, Cambridge, pp 659-708

O'Brien K (2017) Climate change adaptation and social transformation. In: International encyclopedia of geography: people, the earth, Environment and Technology. John Wiley \& Sons, Ltd, Oxford, pp 1-8 
Orlove B, Roncoli C, Kabugo M, Majugu A (2010) Indigenous climate knowledge in southern Uganda: the multiple components of a dynamic regional system. Clim Chang 100:243-265. https://doi.org/10.1007 /s10584-009-9586-2

Pandey R, Maithani N, Aretano R et al (2016) Empirical assessment of adaptation to climate change impacts of mountain households: development and application of an adaptation capability index. J Mt Sci 13:15031514

Park SE, Marshall NA, Jakku E et al (2012) Informing adaptation responses to climate change through theories of transformation. Glob Environ Chang 22:115-126. https://doi.org/10.1016/j.gloenvcha.2011.10.003

Patterson JJ, Thaler T, Hoffmann M et al (2018) Political feasibility of $1.5 \mathrm{C}$ societal transformations: the role of social justice. Curr Opin Environ Sustain 31:1-9. https://doi.org/10.1016/j.cosust.2017.11.002

Pearce TC, Ford JD, Willox AC, Smit B (2015) Inuit traditional ecological knowledge (TEK), subsistence hunting and adaptation to climate change in the Canadian Arctic. Arctic 68:233-245

Pelling M, O’Brien K, Matyas D (2015) Adaptation and transformation. Clim Chang 133:113-127. https://doi. org/10.1007/s10584-014-1303-0

Peppler RA (2017) "It's not balancing out like it should be": perceptions of local climate variability in native Oklahoma. Weather Clim Soc 9:317-329

Pfeiffer L, Lin C-YC (2014) Does efficient irrigation technology lead to reduced groundwater extraction? Empirical evidence. J Environ Econ Manage 67:189-208. https://doi.org/10.1016/j.jeem.2013.12.002

Pittock J, Bjornlund H, Stirzaker R, van Rooyen A (2017) Communal irrigation systems in South-Eastern Africa: findings on productivity and profitability. Int J Water Resour Dev 33:839-847. https://doi.org/10.1080 $/ 07900627.2017 .1324768$

Porter JR, Howden M, Smith P (2017) Considering agriculture in IPCC assessments. Nat Clim Chang 7:680683. https://doi.org/10.1038/nclimate3404

Qazi S, Young W Jr (2014) Disaster relief management and resilience using photovoltaic energy. In: 2014 International Conference on Collaboration Technologies and Systems (CTS). IEEE, pp 628-632

Ray D, Bathgate S, Moseley D et al (2015) Comparing the provision of ecosystem services in plantation forests under alternative climate change adaptation management options in Wales. Reg Environ Chang 15:15011513

Reyes-Garcia V, Paneque-Gálvez J, Luz AC et al (2014) Cultural change and traditional ecological knowledge. An empirical analysis from the Tsimane' in the Bolivian Amazon. Hum Organ 73:162

Riahi K, Kriegler E, Johnson N et al (2015) Locked into Copenhagen pledges - implications of short-term emission targets for the cost and feasibility of long-term climate goals. Technol Forecast Soc Change 90:823. https://doi.org/10.1016/j.techfore.2013.09.016

Russell-Smith J, Monagle C, Jacobsohn M et al (2017) Can savanna burning projects deliver measurable greenhouse emissions reductions and sustainable livelihood opportunities in fire-prone settings? Clim Chang 140:47-61. https://doi.org/10.1007/s10584-013-0910-5

Schleussner C-F, Rogelj J, Schaeffer M et al (2016) Science and policy characteristics of the Paris Agreement temperature goal. Nat Publ Gr. https://doi.org/10.1038/NCLIMATE3096

Schlosberg D, Collins LB, Niemeyer S (2017) Adaptation policy and community discourse: risk, vulnerability, and just transformation. Env Polit 26:413-437. https://doi.org/10.1080/09644016.2017.1287628

Sherman M, Ford J, Llanos-Cuentas A, Valdivia MJ (2016) Food system vulnerability amidst the extreme 20102011 flooding in the Peruvian Amazon: a case study from the Ucayali region. Food Secur 8:551-570. https://doi.org/10.1007/s12571-016-0583-9

Shi L, Chu E, Anguelovski I et al (2016) Roadmap towards justice in urban climate adaptation research. Nat Clim Chang 6:131-137. https://doi.org/10.1038/nclimate2841

Sikka AK, Islam A, Rao KV (2018) Climate-smart land and water management for sustainable agriculture. Irrig Drain 67:72-81. https://doi.org/10.1002/ird.2162

Singh C, Osbahr H, Dorward P (2018) The implications of rural perceptions of water scarcity on differential adaptation behaviour in Rajasthan. India Reg Environ Chang. https://doi.org/10.1007/s10113-018-1358-y

Snilstveit B, Vojtkova M, Bhavsar A, Gaarder M (2013) Evidence gap maps: a tool for promoting evidenceinformed policy and prioritizing future research. World Bank Indep Eval Gr Policy Res:1-34. https://oi. org/10.1596/1813-9450-6725

Snorek J, Renaud FG, Kloos J (2014) Divergent adaptation to climate variability: a case study of pastoral and agricultural societies in Niger. Glob Environ Chang 29:371-386. https://doi.org/10.1016/j. gloenvcha.2014.06.014

Sovacool BK, Linner BO, G ME et al (2015) The political economy of climate adaptation. Nat Clim Chang 5: 616-618. https://doi.org/10.1038/nclimate2665

Sutherland WJ, Wordley CFR (2018) A fresh approach to evidence synthesis. Nature 558:364-366. https://doi. org/10.1038/d41586-018-05472-8 
Thomalla F, Downing T, Spanger-Siegfried E et al (2006) Reducing hazard vulnerability: towards a common approach between disaster risk reduction and climate adaptation. Disasters 30:39-48

Thornton TF, Comberti C (2017) Synergies and trade-offs between adaptation, mitigation and development. Clim Chang 140:5-18. https://doi.org/10.1007/s10584-013-0884-3

Thornton PK, Herrero M (2015) Adapting to climate change in the mixed crop and livestock farming systems in sub-Saharan Africa. Nat Clim Chang 5:830-836. https://doi.org/10.1038/nclimate2754

Thornton PK, Rosenstock T, Förch W et al (2018) A qualitative evaluation of CSA options in mixed croplivestock systems in developing countries. In: Lipper L, McCarthy N, Zilberman D et al (eds) Climate smart agriculture: building resilience to climate change. Springer International Publishing, Cham, pp 385-423

Tschakert P, Barnett J, Ellis N et al (2017) Climate change and loss, as if people mattered: values, places, and experiences. Wiley Interdiscip Rev Clim Chang 8:e476. https://doi.org/10.1002/wcc.476

UNEP (2017) The Adaptation Gap Report 2017. United Nations environment Programme (UNEP), Nairobi, Kenya

van Valkengoed AM, Steg L (2019) Meta-analyses of factors motivating climate change adaptation behaviour. Nat Clim Chang 9:158-163. https://doi.org/10.1038/s41558-018-0371-y

van Vliet MTH, Wiberg D, Leduc S, Riahi K (2016) Power-generation system vulnerability and adaptation to changes in climate and water resources. Nat Clim Chang 6:375-380. https://doi.org/10.1038/nclimate2903

Varela-Ortega C, Blanco-Gutiérrez I, Esteve P et al (2016) How can irrigated agriculture adapt to climate change? Insights from the Guadiana Basin in Spain. Reg Environ Chang 16:59-70. https://doi.org/10.1007 /s10113-014-0720-y

Viner D, Howarth C (2014) Practitioners' work and evidence in IPCC reports. Nat Clim Chang 4:848-850. https://doi.org/10.1038/nclimate2362

Vink MJ, Benson D, Boezeman D et al (2015) Do state traditions matter? Comparing deliberative governance initiatives for climate change adaptation in Dutch corporatism and British pluralism. J Water Clim Chang 6: 71-88. https://doi.org/10.2166/wcc.2014.119

Waisman H, De Coninck H, Rogelj J (2019) Key technological enablers for ambitious climate goals: insights from the IPCC special report on global warming of $1.5^{\circ} \mathrm{C}$. Environ Res Lett 14:111001. https://doi. org/10.1088/1748-9326/ab4c0b

Wamsler C, Niven L, Beery TH et al (2016) Operationalizing ecosystem-based adaptation: Harnessing ecosystem services to buffer communities against climate change. Ecol Soc:21. https://doi.org/10.5751/ES-08266210131

Warner BP, Kuzdas CP (2017) The role of political economy in framing and producing transformative adaptation. Curr Opin Environ Sustain 29:69-74. https://doi.org/10.1016/j.cosust.2017.12.012

Webber S (2016) Climate change adaptation as a growing development priority: towards critical adaptation scholarship. Geogr Compass 10:401-413. https://doi.org/10.1111/gec3.12278

Ziervogel G, Pelling M, Cartwright A et al (2017) Inserting rights and justice into urban resilience: a focus on everyday risk. Environ Urban 29:123-138. https://doi.org/10.1177/0956247816686905

Ziervogel G, Satyal P, Basu R et al (2019) Vertical integration for climate change adaptation in the water sector: lessons from decentralisation in Africa and India. Reg Environ Chang. https://doi.org/10.1007/s10113-01901571-y

Publisher's note Springer Nature remains neutral with regard to jurisdictional claims in published maps and institutional affiliations.

\section{Affiliations}

\section{Chandni Singh $^{1} \cdot$ James Ford $^{2} \cdot$ Debora Ley $^{3} \cdot$ Amir Bazaz $^{1} \cdot$ Aromar Revi $^{1}$}

1 Indian Institute for Human Settlements, Bangalore, India

2 University of Leeds, Leeds, UK

3 Latinoamérica Renovable, Guatemala City, Guatemala 